\title{
A squaraine dye as molecular sensitizer for increasing light harvesting in polymer solar cells
}

Guo Chen ${ }^{\mathrm{a}}$, Hisahiro Sasabe ${ }^{\mathrm{a}, *}$, Xiao-Feng Wang ${ }^{\mathrm{a}}$, Ziruo Hong ${ }^{\mathrm{a}, \mathrm{b}, *}$, Junji Kido ${ }^{\mathrm{a}, *}$

${ }^{a}$ Department of Organic Device Engineering, Graduate School of Science and

Engineering, Research Center for Organic Electronics (ROEL), Yamagata University, 4-3-16 Jonan, Yonezawa, Yamagata 992-8510, Japan.

${ }^{\mathrm{b}}$ Department of Materials Science and Engineering, University of California-Los Angeles, Los Angeles, CA 90095, USA.

Corresponding author. E-mail address: h-sasabe@yz.yamagata-u.ac.jp; zrhong@ucla.edu; kid@yz.yamagata-u.ac.jp

Abstract: In this work, a near-infrared (NIR) absorbing squaraine dye, 2,4-bis[4-(N,Ndiisobutylamino)-2,6-dihydroxyphenyl] squaraine (DIBSQ), was added as a molecular sensitizer into poly(3-hexylthiophene):[6,6]-phenyl-C61-butyric acid methyl ester (P3HT:PCBM) polymer solar cells to improve their power conversion efficiency (PCE). The absorption of the additional DIBSQ contributed to the photoresponse of the cells in the NIR region. The enhancement of light harvesting efficiently increased the short-circuit current density, and thus improved the PCE by $\sim 10 \%$. The optimized PCE of $3.4 \%$ under 1 sun, AM $1.5 \mathrm{G}$ solar irradiation was achieved with the DIBSQ:P3HT:PCBM system that included 3 or $5 \mathrm{wt} \%$ of DIBSQ. Our results show that 
DIBSQ is a promising molecular sensitizer for increasing the PCE of P3HT:PCBM polymer solar cells.

Keywords: Squaraine dye, molecular sensitizer, organic solar cell, bulk heterojunction, light harvesting

\section{Introduction}

Organic bulk heterojunction (BHJ) solar cells based on blends of donor and acceptor materials have attracted increased attention owing to their advantages of low cost, easy fabrication, light weight, and the possibility of fabricating flexible devices [1-4]. In the BHJ solar cell family, the most widely investigated device is the polymer solar cell based on poly(3-hexylthiophene) (P3HT) as the donor and [6,6]-phenyl-C61-butyric acid methyl ester (PCBM) as the acceptor. Researchers have achieved power conversion efficiencies (PCEs) in P3HT:PCBM devices that exceed 4\% through several device optimization strategies [5-8] such as thermal treatments [5], solvent annealing [6], and mixed-solvent treatments [7,8]. However, further improvement of PCEs is limited because the relatively large band gap of P3HT $(\sim 1.9 \mathrm{eV})$ limits the wavelength of the harvested solar light to $650 \mathrm{~nm}$ [9]. A promising way to improve device performance is to blend additional near-infrared (NIR) absorbing donors into P3HT:PCBM films 
[10-16]. The enhanced longer-wavelength absorption from the additional donor can improve the photocurrent and PCE of the devices. Blended P3HT:PCBM films contain networks with almost ideal phase separation, which enables small concentrations of additional materials to be introduced into the P3HT:PCBM system without disturbing the morphology of the resulting film.

Recently, some low band gap small molecular materials have also been reported to serve as donors in BHJ solar cells. However, achieving good film morphology in small molecule-based solar cells is challenging, because the amorphous properties of the blended films result in a significant recombination loss of the photogenerated charge carriers [17]. Therefore, the fill factor (FF) of this type of solar cell is normally less than 50\% [18]. Squaraine dyes are considered as promising small molecular donors for organic solar cells because of their intense absorption in the long-wavelength region and their considerable photo- and thermal-stability under ambient conditions [19-21]. For example, 2,4-bis[4-(N,N-diisobutylamino)-2,6-dihydroxyphenyl] squaraine (DIBSQ) (Fig. 1a), a squaraine dye that exhibits NIR absorption and moderate solubility in halogenated organic solvents, has been used as a donor material for solution-processed solar cells [22,23]. However, the PCEs of DIBSQ-based BHJ solar cells are primarily limited by their relatively small FF, which can be ascribed to the low mobility of 
DIBSQ $\left(\sim 3.5 \times 10^{-5} \mathrm{~cm}^{2} / \mathrm{Vs}\right)$ [23]. Much room, therefore, exists for further improvement in the performance of DIBSQ-based solar cells via morphological control. Given the advantages and disadvantages of P3HT and DIBSQ as donor materials for organic solar cells, we propose that introducing DIBSQ into a P3HT:PCBM BHJ system is an efficient way to improve device performance.

In this work, to improve the PCE of P3HT:PCBM polymer solar cells, we used DIBSQ (Fig. 1a) as a molecular sensitizer having poor mobility but intense NIR absorption into the P3HT:PCBM host to form a dual donor system. Our results show that the photoresponse of the solar cells can be extended to the NIR range when small concentrations of DIBSQ are added into P3HT:PCBM BHJ films. The enhancement of light harvesting increases the short-circuit current density $\left(\mathrm{J}_{\mathrm{sc}}\right)$, thereby improving the overall PCE.

\section{Experimental}

The DIBSQ dye used in this work was synthesized according to the literature procedure [24] and purified by high-vacuum sublimation. P3HT and PCBM were commercially purchased and used as received. The blend solution of DIBSQ:P3HT:PCBM was prepared as follows: P3HT was dissolved in o-dichlorobenzene $(20 \mathrm{mg} / \mathrm{mL})$, and the solution was stirred at $40{ }^{\circ} \mathrm{C}$ for $10 \mathrm{~h}$. PCBM 
(20 $\mathrm{mg} / \mathrm{mL}$ ) and DIBSQ (weight ratios of DIBSQ to P3HT were 3 , 5 , and $10 \mathrm{wt} \%$ ) were subsequently added to the P3HT solution. The blend solution was then stirred for $10 \mathrm{~h}$ and filtered through a $0.2 \mu \mathrm{m}$ filter before use.

Patterned indium-tin-oxide (ITO)-coated glass substrates were sequentially cleaned using detergent, deionized water, acetone, and isopropanol in an ultrasonic bath. The cleaned substrates were dried in an oven and then subjected to an ultraviolet/ozone treatment for $30 \mathrm{~min}$. The substrates were then immediately spin-coated with a $\sim 30 \mathrm{~nm}$ thick layer of poly(3,4-ethylene dioxythiophene):poly(styrenesulfonate) (PEDOT:PSS) (Clevios P VP.AI 4083) and subsequently heated in air for $20 \mathrm{~min}$ at $120^{\circ} \mathrm{C}$ to remove the residual water. The active layers, i.e., P3HT:PCBM as a reference and DIBSQ:P3HT:PCBM ( 200 nm), were spin-coated onto the PEDOT:PSS films at 700 rpm for $28 \mathrm{~s}$ in a $\mathrm{N}_{2}$-filled glove box [6]. The wet films were slowly and completely dried in covered glass Petri dishes. Later, the samples were thermally annealed: the P3HT:PCBM film was annealed at $110^{\circ} \mathrm{C}$ for $10 \mathrm{~min}$, and the DIBSQ:P3HT:PCBM films were annealed at various temperatures for $10 \mathrm{~min}$. Finally, the films were transferred to a high-vacuum chamber $\left(5 \times 10^{-6} \mathrm{~Pa}\right)$, where the top electrode $(20 \mathrm{~nm} \mathrm{Ca}$, $80 \mathrm{~nm} \mathrm{Al)} \mathrm{was} \mathrm{evaporated} \mathrm{through} \mathrm{a} \mathrm{mask,} \mathrm{leading} \mathrm{to} \mathrm{four} \mathrm{solar} \mathrm{cells} \mathrm{with} \mathrm{an} \mathrm{active} \mathrm{area}$ of $4 \mathrm{~mm}^{2}$ on each substrate. The final device structure was 
ITO/PEDOT:PSS/DIBSQ:P3HT:PCBM/Ca/Al; the energy diagrams of the device are shown in Fig. 1b. The hole-only and electron-only devices were fabricated using the structures of ITO/PEDOT:PSS/P3HT:PCBM (or DIBSQ:P3HT:PCBM)/MoO3/Al and ITO/Cs $\mathrm{CO}_{3} / \mathrm{P} 3 \mathrm{HT}: \mathrm{PCBM}$ (or DIBSQ:P3HT:PCBM)/Ca/Al, respectively, to characterize carrier mobilities in blended films by the space-charge-limited current (SCLC) method [23]. Both current-voltage $(\mathrm{J}-\mathrm{V})$ characteristics and external quantum efficiency (EQE) spectra of the devices were measured under standard measurement conditions on a CEP-2000 integrated system manufactured by Bunkoukeiki Co. [25-27]. Bright-state J-V characteristics were measured under simulated $100 \mathrm{~mW} / \mathrm{cm}^{2}$ AM $1.5 \mathrm{G}$ irradiation from a Xe lamp equipped with an AM 1.5 global filter. EQE spectra were measured using a Xe lamp, a monochromator, an optical chopper, and a lock-in amplifier.

UV-visible (UV-vis) absorption spectra were obtained using a SHIMADZU MPC-2200 UV-visible spectrophotometer. The morphology of the P3HT:PCBM and DIBSQ:P3HT:PCBM films was analyzed by atomic force microscopy (AFM) and X-ray diffraction (XRD). AFM images were collected in air on a Veeco AFM using a tapping mode. XRD patterns were performed using a high-resolution XRD diffractometer (SmartLab, Rigaku Co.). The films for AFM and XRD measurements were prepared by 
spin coating the P3HT:PCBM (or DIBSQ:P3HT:PCBM) solution onto the PEDOT:PSS-coated ITO substrates.

\section{Results and discussion}

Fig. 2a demonstrates the UV-vis absorption spectra of thin films of neat DIBSQ, P3HT, PCBM, and the blend of P3HT:PCBM and DIBSQ:P3HT:PCBM with 3, 5, and $10 \mathrm{wt} \%$ DIBSQ/P3HT weight ratios. The spectrum of the DIBSQ film shows an absorption band in the region of 500 760 nm; the spectrum of the P3HT film shows a wide absorption band between 300 and $650 \mathrm{~nm}$; and that of the PCBM film shows absorption at short wavelengths of blue and green. Thus, the broad and intense absorption at 300 400 $\mathrm{nm}$ and 400 640 $\mathrm{nm}$ in the spectra of DIBSQ (3, 5, and 10 wt\%):P3HT:PCBM blended films can be ascribed to the absorption of PCBM and P3HT, respectively. The enhanced absorption in the $630-800 \mathrm{~nm}$ range relative to that shown in the absorption spectrum of the P3HT:PCBM film stems from the absorption of DIBSQ, which contributes to longer-wavelength light harvesting, and thus potentially improves the photocurrent of the P3HT:PCBM BHJ cells.

A comparison of the spectra of the blend films with the spectrum of the pure DIBSQ film reveals that the absorption band of DIBSQ is obviously narrower and blue-shifted with decreasing DIBSQ concentration (Fig. 2a), this result indicates that DIBSQ 
molecules tend to disperse in the blend films rather than aggregate [23]. High mobility in the P3HT blend films should be maintained via self-organization [6]. The characteristic peaks of $\pi-\pi$ stacking of P3HT at 560 and $610 \mathrm{~nm}$ are as strong as those in the films without DIBSQ, which confirms that the morphology of P3HT:PCBM blend films with a low concentration of DIBSQ is not disturbed.

The J-V characteristics and EQE spectra of the BHJ devices based on $5 \mathrm{wt} \%$ DIBSQ:P3HT:PCBM blend films are shown in Fig. 3 together with those of the reference P3HT:PCBM cell for comparison. The relative photovoltaic parameters are summarized in Table 1. As shown in Fig. 3 and Table 1, compared with $\mathrm{J}_{\mathrm{sc}}$ of the reference P3HT:PCBM cell that of the $5 \mathrm{wt} \%$ DIBSQ:P3HT:PCBM cell obviously improved $\left(8.4 \pm 0.1\right.$ to $\left.9.3 \pm 0.1 \mathrm{~mA} / \mathrm{cm}^{2}\right)$, which is ascribed to the enhancement of light-harvesting efficiency in the long-wavelength region of 630-800 nm. However, FF decreases from $0.63 \pm 0.01$ to $0.56 \pm 0.01$. We annealed the $5 \mathrm{wt} \%$ DIBSQ:P3HT:PCBM blend film at an elevated temperature, because thermal annealing has been shown to effectively enhance the FF of organic solar cells via phase separation and mobility enhancement $[5,6]$. The devices based on the films annealed at $70{ }^{\circ} \mathrm{C}$ for $10 \mathrm{~min}$ show an optimal efficiency of $3.3 \pm 0.1 \%$ with $\mathrm{J}_{\mathrm{sc}}$ of $9.3 \pm 0.1 \mathrm{~mA} / \mathrm{cm}^{2}$, open circuit voltage $\left(\mathrm{V}_{\mathrm{oc}}\right)$ of $0.58 \pm 0.01 \mathrm{~V}$, and $\mathrm{FF}$ of $0.60 \pm 0.01$. When the film annealing temperature was 
further increased to 110,130 or $150{ }^{\circ} \mathrm{C}$, the $\mathrm{V}_{\text {oc }}$ and $\mathrm{FF}$ remained almost unchanged whereas the $\mathrm{J}_{\mathrm{sc}}$ gradually decreased, which resulted in diminished device performance. Fig. $2 b$ shows the optical absorption spectra of 5wt\% DIBSQ:P3HT:PCBM films subjected to thermal treatments at various temperatures. The shoulder peaks of P3HT at 560 and $610 \mathrm{~nm}$ were slightly enhanced by the thermal treatment at $70{ }^{\circ} \mathrm{C}$ for $10 \mathrm{~min}$ and then gradually decreased in intensity as the annealing temperature was increased further. This trend is consistent with that in the EQE spectra (Fig. 3b). Though the films maintain their photoresponse in the NIR range, the EQE spectra show an obvious decrease across the entire visible range. Notably, the highest occupied molecular orbital level of DIBSQ is deeper than that of P3HT (Fig. 1b). Therefore, the additional DIBSQ in the P3HT:PCBM BHJs does not induce any charge-trapping effects. The decrease in intensity in the EQE spectra can be explained by the diffusion of DIBSQ into P3HT domains, reducing the crystallinity of and carrier mobility in the P3HT (Table 2) [6], which will later be demonstrated through film morphology analysis and carrier mobility characterization.

The weight ratio of DIBSQ in the P3HT:PCBM blend system is another key factor in achieving optimal photovoltaic performance. During fabrication of the DIBSQ:P3HT:PCBM BHJ devices with various concentrations of DIBSQ, the thermal 
annealing temperature was maintained at $70{ }^{\circ} \mathrm{C}$. The results (Fig. 4a, Table 2) reveal that when the concentration of DIBSQ in the blend system was decreased to $3 \mathrm{wt} \%$ DIBSQ:P3HT:PCBM, PCE of $3.3 \pm 0.1 \%$ with $\mathrm{J}_{\mathrm{sc}}$ of $9.2 \pm 0.1 \mathrm{~mA} / \mathrm{cm}^{2}, \mathrm{~V}_{\text {oc }}$ of $0.58 \pm 0.01$ $\mathrm{V}$, and FF of $0.61 \pm 0.01$ was achieved, and the device performance was similar to that of the $5 \mathrm{wt} \%$ DIBSQ:P3HT:PCBM device. When loading of DIBSQ in the blend system was further reduced to $2 \mathrm{wt} \%$ DIBSQ:P3HT:PCBM, performance of the device was approximately equal to that of the P3HT:PCBM reference cell (data not shown). Therefore, 3\% was set as the minimum DIBSQ concentration in the DIBSQ:P3HT:PCBM system. However, when loading of DIBSQ in the blend system was increased to $10 \mathrm{wt} \%$, the PCE of the BHJ device dramatically decreased to $2.7 \pm 0.1 \%$ with a decreased $\mathrm{J}_{\mathrm{sc}}$ of $8.5 \pm 0.1 \mathrm{~mA} / \mathrm{cm}^{2}$, an unchanged $\mathrm{V}_{\mathrm{oc}}$ of $0.59 \pm 0.01 \mathrm{~V}$, and a decreased FF of $0.54 \pm 0.01$. In the interim, the series resistance of the BHJ device increased to $19.3 \Omega \mathrm{cm}^{2}$, whereas the hole and electron mobilities in the BHJ film decreased to $9.57 \times 10^{-5}$ and $5.58 \times 10^{-4} \mathrm{~cm}^{2} / \mathrm{Vs}$ (as shown in Table 2), respectively. The significantly decreased carrier mobility resulted in a dramatic decrease in $\mathrm{J}_{\mathrm{sc}}$, and the increased series resistance and decreased carrier mobilities led to the decrease in FF in the $10 \mathrm{wt} \%$ DIBSQ:P3HT:PCBM BHJ system. Although the intensity in the NIR range of the EQE spectrum of $10 \mathrm{wt} \%$ DIBSQ:P3HT:PCBM cell was higher than those 
of other devices, it decreased by more than $20 \%$ in the visible range (Fig. $4 \mathrm{~b}$ ), which is consistent with the decrease in $\mathrm{J}_{\mathrm{sc}}$ of the $10 \mathrm{wt} \%$ DIBSQ:P3HT:PCBM cell.

To study the effect of the additional DIBSQ on the film morphology, we used AFM images and XRD patterns to analyze the morphology of the DIBSQ:P3HT:PCBM films and compared the results with those obtained for the reference P3HT:PCBM film. The films for AFM images and XRD patterns were prepared under the same conditions used for fabricating the devices to enable accurate comparisons. As shown in the AFM image in Fig. 5, the reference P3HT:PCBM film shows a crystalline morphology with a root-mean-square roughness of $7.24 \mathrm{~nm}$. When the concentration of DIBSQ in the blend film was increased from 3 to $10 \mathrm{wt} \%$, the RMS values of the films sequentially decreased, which means that the additional DIBSQ slightly reduced the crystallinity of the film. The topographic images show highly ordered fibrillar crystalline domains of P3HT in the blend films of P3HT:PCBM and DIBSQ:P3HT:PCBM with lower DIBSQ concentrations of 3 and $5 \mathrm{wt} \%$. However, when the concentration of DIBSQ was increased to $10 \mathrm{wt} \%$, the highly ordered fibrillar crystalline domains of P3HT were almost absent (Fig. 5d), which indicates that addition of $10 \mathrm{wt} \%$ DIBSQ to the film obviously disturbed the film morphology. The disturbed film morphology may also be responsible for poor device performance of the $10 \mathrm{wt} \%$ DIBSQ:P3HT:PCBM BHJ cell. 
Notably, the XRD results (Fig. 6) are in agreement with the AFM images. The diffraction peak at $2 \theta=5.3^{\circ}$ in the XRD pattern of $\mathrm{P} 3 \mathrm{HT}: \mathrm{PCBM}$ film corresponds to the interchain spacing in P3HT [28]. The introduction of a greater concentration of DIBSQ into the film (i.e., $10 \mathrm{wt} \%$ ) obviously resulted in a decreased intensity of the P3HT diffraction peak. The AFM images and XRD spectra further indicate that low concentrations of DIBSQ in the P3HT:PCBM system do not substantially disturb the film morphology, which is consistent with the results related to film absorption and device performance.

\section{Summary}

In conclusion, we investigated the effect of squaraine dye, DIBSQ, as a molecular sensitizer on the photovoltaic performance of P3HT:PCBM polymer solar cells. The morphological analysis results demonstrated that low concentrations of the DIBSQ dye do not substantially disturb the film morphology. In comparison to the P3HT:PCBM reference cell, the cells with $3 \sim 5 \%$ DIBSQ as an additive exhibit extended photoresponses in the NIR region, and thus exhibit improved $\mathrm{J}_{\mathrm{sc}}$ values without compromising $\mathrm{V}_{\text {oc }}$ and FF, thereby resulting in $\sim 10 \%$ enhancement in PCE. Our results show that DIBSQ is an efficient molecular sensitizer for improving the performance of P3HT:PCBM polymer solar cells. 
Acknowledgements: We thank the Japan Science and Technology Agency (JST) via the Japan Regional Innovation Strategy Program by the Excellence (J-RISE) and the Adaptable and Seamless Technology Transfer Program (A-STEP, AS232Z00929D and AS251Z00216M) for their financial support. Moreover, the authors are grateful to thank

Prof. Y. Yang at UCLA for scientific discussions, and Dr. K. Nakayama, Dr. D. Yokoyama, and Dr. J. Hu for their technical assistance and scientific discussions.

\section{References}

[1] G. Yu, J. Gao, J. C. Hummelen, F. Wudl, A. J. Heeger, Science 270 (1995) 1789.

[2] S. Günes, H. Neugebauer, N. S. Sariciftci, Chem. Rev. 107 (2007) 1324.

[3] G. Li, R. Zhu, Y. Yang, Nat. Photonics 6 (2012) 153.

[4] T. Ameri, P. Khoram, J. Min, C. J. Brabec, Adv. Mater. 25 (2013) 4245.

[5] W. L. Ma, C. Y. Yang, X. Gong, K. H. Lee, A. J. Heeger, Adv. Funct. Mater. 15 (2005) 1617.

[6] G. Li, V. Shrotriya, J. S. Huang, Y. Yao, T. Moriarty, K. Emery, Y. Yang, Nat. Mater. 4 (2005) 864.

[7] A. J. Moulé, K. Meerholz, Adv. Mater. 20 (2008) 240. 
[8] Y. Yao, J. H. Hou, Z. Xu, G. Li, Y. Yang, Adv. Funct. Mater. 18 (2008) 1783.

[9] G. J. Zhao, Y. J. He, Y. F. Li, Adv. Mater. 22 (2010) 4355.

[10] S. Honda, T. Nogami, H. Ohkita, H. Benten, S. Ito, ACS Appl. Mater. Interfaces 1 (2009) 804.

[11] J. Peet, A. B. Tamayo, X. D. Dang, J. H. Seo, T. Q. Nguyen, Appl. Phys. Lett. 93 (2008) 163306.

[12] S. Honda, H. Ohkita, H. Benten, S. Ito, Chem. Commun. 46 (2010) 6596.

[13] S. S. Sharma, G. D. Sharma, J. A. Mikroyannidis, Sol. Energy Mater. Sol. Cells 95 (2011) 1219.

[14] S. Honda, H. Ohkita, H. Benten, S. Ito, Adv. Energy Mater. 1 (2011) 588.

[15] Y. J. Cho, J. Y. Lee, B. D. Chin, S. R. Forrest, Organic Electronics 14 (2013) 108.

[16] J. S. Huang, T. Goh, X. Li, M. Y. Sfeir, E. A. Bielinski, S. Tomasulo, M. L. Lee, N. Hazari, A. D. Taylor, Nature Photonics 7 (2013) 479.

[17] Y. Sun, G. C. Welch, W. L. Leong, C. J. Takacs, G. C. Bazan, A. J. Heeger, Nat. Mater. 11 (2011) 44.

[18] B. Walker, C. Kim, T. Q. Nguyen, Chem. Mater. 23 (2011) 470.

[19] F. Silvestri, M. D. Irwin, L. Beverina, A. Facchetti, G. A. Pagani, T. J. Marks, J. Am. Chem. Soc. 130 (2008) 17640. 
[20] U. Mayerhöffer, K. Deing, K. Gruß, H. Braunschweig, K. Meerholz, F. Würthner, Angew. Chem. Int. Ed. 48 (2009) 8776.

[21] G. Chen, H. Sasabe, L. Wei, X. F. Wang, J. Kido, Z. Hong, Y. Yang, J. Mater. Chem. C 1 (2013) 6547.

[22] G. Wei, S. Wang, K. Renshaw, M. E. Thompson, S. R. Forrest, ACS Nano 4 (2010) 1927.

[23] G. Chen, H. Sasabe, Z. Wang, X. Wang, Z. Hong, J. Kido, Y. Yang, Phys. Chem. Chem. Phys. 14 (2012) 14661.

[24] M. Q. Tian, M. Furuki, I. Iwasa, Y. Sato, L. S. Pu, S. Tatsuura, J. Phys. Chem. B $106(2002) 4370$.

[25] V. Shrotriya, G. Li, Y. Yao, T. Moriarty, K. Emery, Y. Yang, Adv. Funct. Mater. 16 (2006) 2016.

[26] G. Chen, H. Sasabe, Z. Wang, X. F. Wang, Z. Hong, Y. Yang, J. Kido, Adv. Mater. 24 (2012) 2768.

[27] G. Chen, D. Yokoyama, H. Sasabe, Z. Hong, Y. Yang, J. Kido, Appl. Phys. Lett. $101(2012) 083904$.

[28] W. L. Ma, C. Y. Yang, X. Gong, K. Lee, A. J. Heeger, Adv. Funct. Mater. 15 (2005) 1617. 
a)

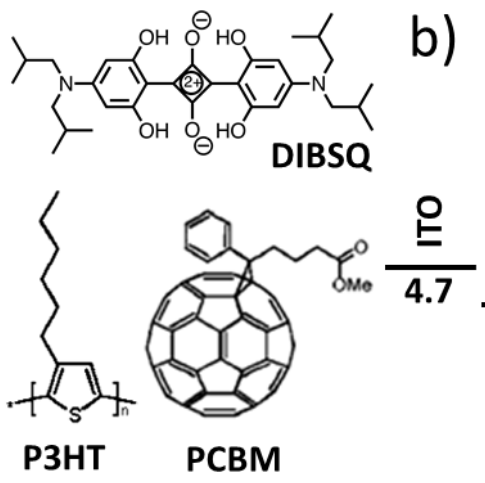

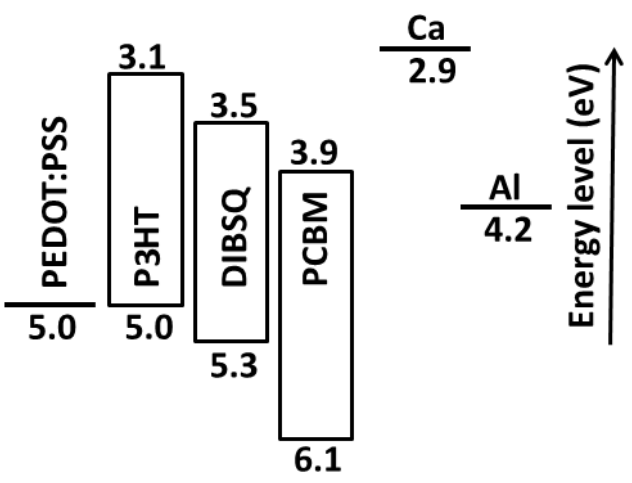

Fig. 1. a) Molecular structures of DIBSQ, P3HT, and PCBM; b) energy diagrams of the DIBSQ:P3HT:PCBM bulk heterojunction cells. 

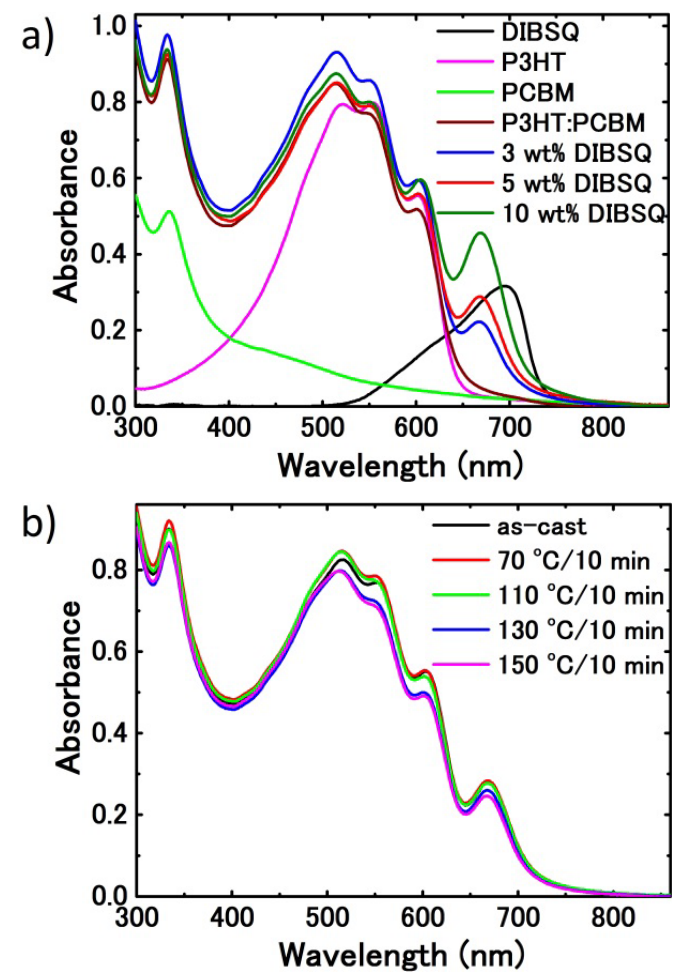

Fig. 2. a) UV-vis absorption spectra of DIBSQ, P3HT, PCBM, P3HT:PCBM, 3 wt $\%, 5$ wt $\%$, and 10 wt $\%$ DIBSQ:P3HT:PCBM films; b) UV-vis absorption spectra of the as-cast and $5 \mathrm{wt} \%$ DIBSQ:P3HT:PCBM films annealed at different temperatures. 

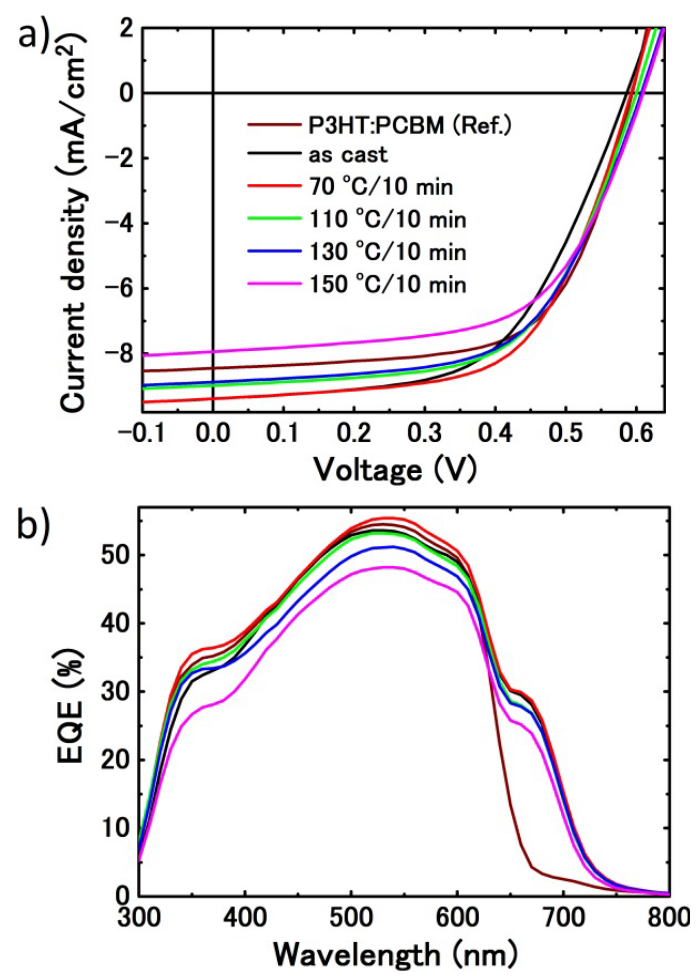

Fig. 3. Comparison of the a) J-V characteristics illuminated under AM 1.5 G solar spectrum at $100 \mathrm{~mW} / \mathrm{cm}^{2}$ illumination; and b) EQE spectra of the $5 \mathrm{wt} \%$ DIBSQ:P3HT:PCBM cells fabricated with films annealed at various temperatures with that of the reference P3HT:PCBM cell. 

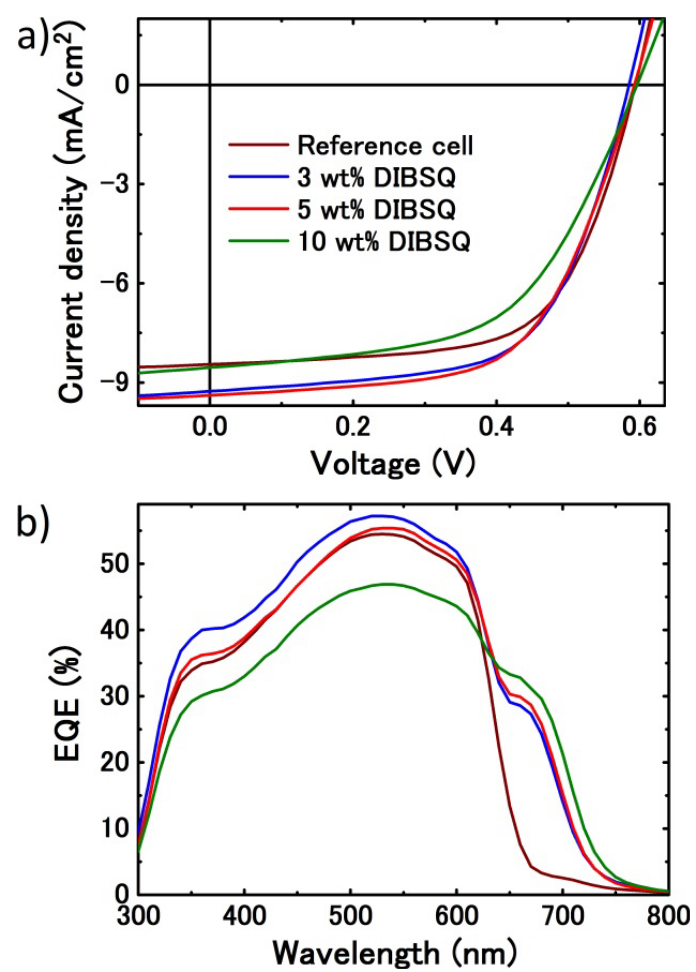

Fig. 4. Comparison of the a) J-V characteristics illuminated under AM 1.5 G solar spectrum at $100 \mathrm{~mW} / \mathrm{cm}^{2}$ illumination; and b) EQE spectra of the DIBSQ:P3HT:PCBM cells with various concentrations of DIBSQ with that of the reference P3HT:PCBM cell. 
a)

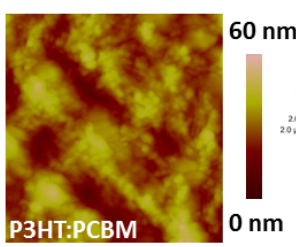

c)

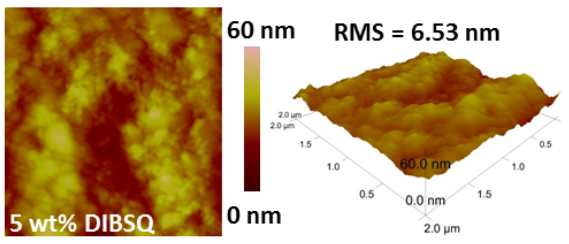

b)

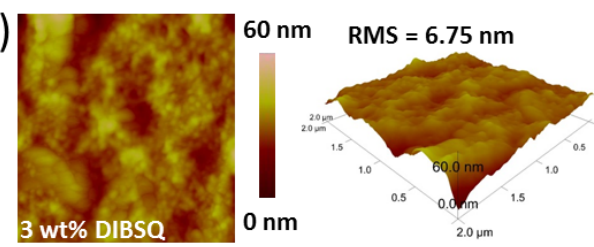

d)

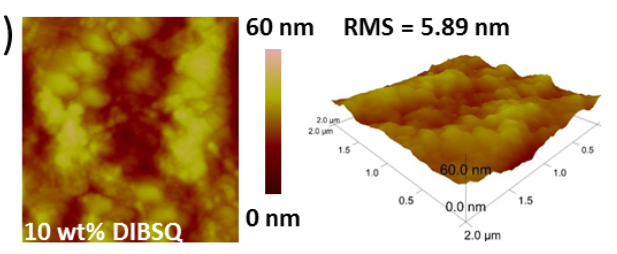

Fig. 5. Atomic force microscopy (AFM) topographic and 3D images of the films spin-coated onto ITO/PEDOT:PSS substrates using the same procedures used for fabrication of the devices: a) the reference P3HT:PCBM film annealed at $110{ }^{\circ} \mathrm{C}$ for 10 min; b)-d) the DIBSQ:P3HT:PCBM films with various concentrations of DIBSQ annealed at $70{ }^{\circ} \mathrm{C}$ for $10 \mathrm{~min}$. 


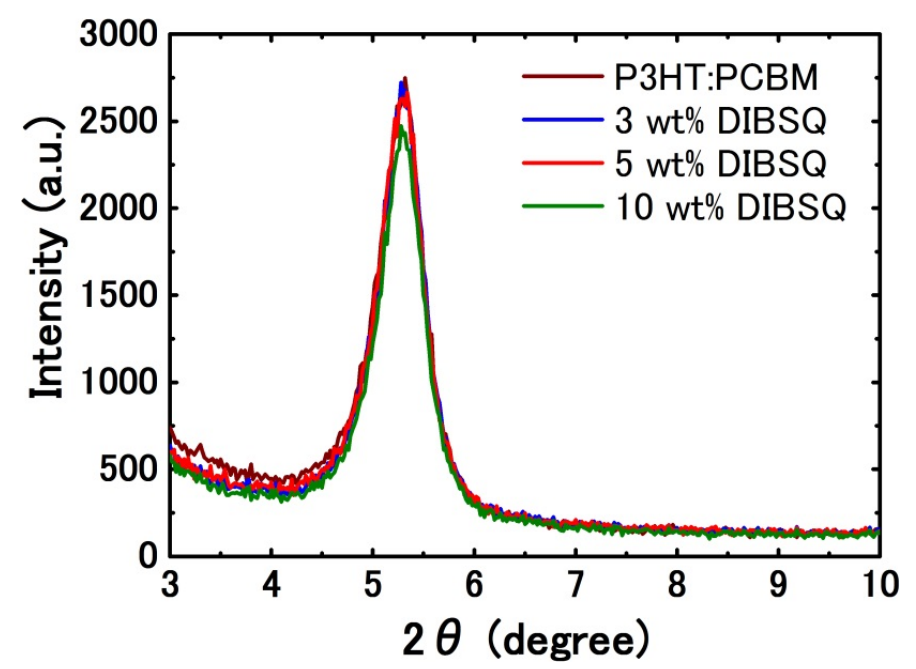

Fig. 6. Comparison of the X-ray diffraction (XRD) patterns of DIBSQ:P3HT:PCBM films with various concentrations of DIBSQ with the XRD pattern of the reference P3HT:PCBM film. 
Table 1. Device performance of $5 \mathrm{wt} \%$ DIBSQ:P3HT:PCBM cells with active layers annealed at various temperatures.

\begin{tabular}{lllll}
\hline Temperature $\left({ }^{\circ} \mathrm{C}\right)$ & $\mathrm{J}_{\mathrm{sc}}\left(\mathrm{mA} / \mathrm{cm}^{2}\right)$ & $\mathrm{V}_{\mathrm{oc}}(\mathrm{V})$ & $\mathrm{FF}$ & PCE $(\%)$ \\
\hline P3HT:PCBM (reference) & $8.4 \pm 0.1$ & $0.58 \pm 0.01$ & $0.63 \pm 0.01$ & $3.0 \pm 0.1$ \\
As-cast & $9.3 \pm 0.1$ & $0.58 \pm 0.01$ & $0.56 \pm 0.01$ & $3.0 \pm 0.1$ \\
70 & $9.3 \pm 0.1$ & $0.58 \pm 0.01$ & $0.60 \pm 0.01$ & $3.3 \pm 0.1$ \\
110 & $8.9 \pm 0.1$ & $0.59 \pm 0.01$ & $0.59 \pm 0.01$ & $3.1 \pm 0.1$ \\
130 & $8.8 \pm 0.1$ & $0.60 \pm 0.01$ & $0.58 \pm 0.01$ & $3.0 \pm 0.1$ \\
150 & $7.9 \pm 0.1$ & $0.60 \pm 0.01$ & $0.59 \pm 0.01$ & $2.8 \pm 0.1$ \\
\hline
\end{tabular}


Table 2. Device performance of DIBSQ:P3HT:PCBM cells with various amounts of DIBSQ.

\begin{tabular}{|c|c|c|c|c|c|c|c|}
\hline Device & $\begin{array}{l}\mathrm{J}_{\mathrm{sc}} \\
\left(\mathrm{mA} / \mathrm{cm}^{2}\right)\end{array}$ & $\mathrm{V}_{\mathrm{oc}}(\mathrm{V})$ & $\mathrm{FF}$ & PCE (\%) & $\begin{array}{l}{ }^{\mathrm{a}} \mathrm{R}_{\mathrm{s}} \\
\left(\Omega \mathrm{cm}^{2}\right)\end{array}$ & ${ }^{\mathrm{b}} \mu_{\mathrm{h}}\left(\mathrm{cm}^{2} / \mathrm{Vs}\right)$ & ${ }^{\mathrm{b}} \mu_{\mathrm{e}}\left(\mathrm{cm}^{2} / \mathrm{Vs}\right)$ \\
\hline P3HT:PCBM (reference) & $8.4 \pm 0.1$ & $0.58 \pm 0.01$ & $0.63 \pm 0.01$ & $3.0 \pm 0.1$ & 11.2 & $4.85 \times 10^{-4}$ & $7.32 \times 10^{-4}$ \\
\hline 3 wt $\%$ DIBSQ:P3HT:PCBM & $9.2 \pm 0.1$ & $0.58 \pm 0.01$ & $0.61 \pm 0.01$ & $3.3 \pm 0.1$ & 11.6 & $3.66 \times 10^{-4}$ & $7.16 \times 10^{-4}$ \\
\hline 5 wt\%DIBSQ:P3HT:PCBM & $9.3 \pm 0.1$ & $0.58 \pm 0.01$ & $0.60 \pm 0.01$ & $3.3 \pm 0.1$ & 13.6 & $2.24 \times 10^{-4}$ & $7.18 \times 10^{-4}$ \\
\hline $10 \mathrm{wt} \%$ DIBSQ:P3HT:PCBM & $8.5 \pm 0.1$ & $0.59 \pm 0.01$ & $0.54 \pm 0.01$ & $2.7 \pm 0.1$ & 19.3 & $9.57 \times 10^{-5}$ & $5.58 \times 10^{-4}$ \\
\hline
\end{tabular}

${ }^{a} R_{s}$ was calculated from the optimized device in each case. ${ }^{b}$ Hole mobility $\left(\mu_{h}\right)$ and electron mobility $\left(\mu_{\mathrm{e}}\right)$ were characterized using the SCLC method. 


\section{Graphical Abstract}

\section{A squaraine dye as molecular sensitizer for increasing light harvesting in polymer solar cells}

Guo Chen ${ }^{\mathrm{a}}$, Hisahiro Sasabe ${ }^{\mathrm{a},{ }^{*}}$, Xiao-Feng Wang ${ }^{\mathrm{a}}$, Ziruo Hong ${ }^{\mathrm{abb},{ }^{*}}$, Junji Kido ${ }^{\mathrm{a},{ }^{*}}$
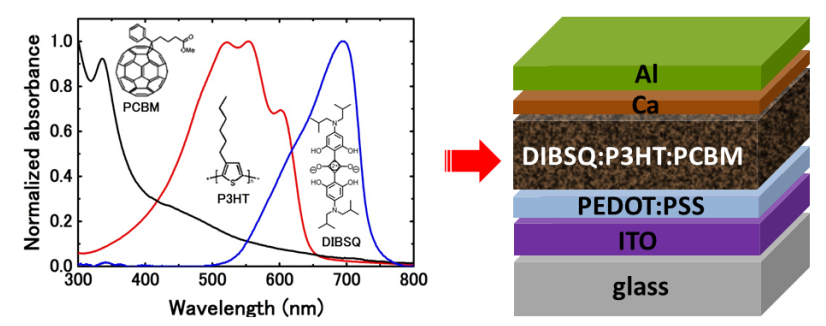

A near-infrared absorbing squaraine dye, DIBSQ, was added as a molecular sensitizer into P3HT:PCBM polymer solar cells to improve their power conversion efficiency. 